\title{
Do indivíduo blasé aos sujeitos cismados: reflexões antropológicas sobre as políticas de reconhecimento na contemporaneidade ${ }^{1}$
}

From the individual blasé to the schism: anthropological reflections on the policies of recognition in contemporary times

\section{Fabio Reis Mota}

Doutor em Antropologia pela Universidade Federal Fluminense (UFF) (com estágio doutoral na UPX $e$ École des hautes études em Sciences sociales (EHESS) Paris). Professor do Departamento e do Programa de Pós-Graduação em Antropologia da Universidade Federal Fluminense (PPGA/UFF). Coordenador do Núcleo Fluminense de Estudos e Pesquisa (NUFEP/UFF). Pesquisador do Instituto de Estudos Comparados em Administração Institucional de Conflitos (InEAC-UFF).

\section{Resumo}

Este artigo visa discutir como o que denomino de regime do cisma tem ocupado um lugar central às relações sociais e sociabilidades das grandes metrópoles. Tomando emprestado dados etnográficos de diferentes fontes de pesquisa, individual e coletiva, problematizo como as dimensões do cisma têm circunscrito os ritmos das políticas ordinárias do reconhecimento. Estabeleço uma diferença entre desconfiar e cismar, de forma a acentuar aspectos contemporâneos das socialidades urbanas.

Palavras-chave: Cisma, Reconhecimento, Identidade, Violência.

\section{Abstract}

The present article aims to discuss how what I call the regime of the schism has occupied a central place to the social relations and sociabilities of the great metropolis. Borrowing ethnographic data from different sources of research, both individual and collective, I problematize how the dimensions of schism has circumscribed the rhythms of ordinary politics of recognition. I establish a difference between distrust and schism in order to accentuate contemporary aspects of urban socialities.

Keywords: Schism, Recognition, Identity, Violence.

Gostaria de agradecer a gentileza pela revisão e normalização feita por Luiza Aragon Ovalle e Alexandre Oliveira Silva, pesquisadores do NUFEP e InEAC da UFF. 


\section{AS ENTRADAS}

Excertos de notas etnográficas de acontecimentos urbanos nas grandes cidades (sob a inspiração de Passant Consideráble, de Isaac Joseph):

"A noite lutava, no declínio das luzes, pela manutenção das vibrações que se apresentavam no percurso do encontro amigável entre Josias e Tobias. A amizade de muitos anos, ritmada pela boêmia, faziam as palavras percorrerem o tempo e sucumbirem às linhas tênues do anoitecer-amanhecer. Embebidos, e embriagados pelo espírito de faire le commun, Josias e Tobias, no desalinho dos reajustes da vida social, decidem se embrenhar pelas fronteiras da metrópole carioca. Esse alargamento da experiência noturna além da fronteira do chamado "asfalto" leva Josias e Tobias ao destino de uma favela na captura da manutenção do regozijo. A cidade os consome e eles, portanto, almejam consumir a cidade (e o que há nela em suas múltiplas formas materiais e imateriais). Entram pela ruela da favela, em um carro popular fazendo esgarçar as passagens e possibilidades de 'transações intersubjetivas' (como diria Ricoeur) oferecidas pelo universo de instabilidade, imprevisibilidade no mundo da comunicação do possível. Tobias e Josias não se intimidam com o cerceamento imposto pelas imagens impressas nos muros com dizeres de morte e fé, lembrança e dor. Nessas ruas escuras, onde reina a violência como linguagem, Josias e Tobias percorrem sua rota.

O carro avança vagarosamente, ostentando os signos usuais exigidos para a circulação nas favelas das cidades fluminenses (pisca alerta ligado, vidro aberto, velocidade baixa), em um raio de segundos Tobias e Josias se dão conta que pistolas se impunham em suas direções. Os rapazes, todos jovens negros e pardos, com bermudas, tênis e camisas apontam suas armas com ar de pouca prosa. Josias e Tobias descem do carro com os braços para o alto, levantando suas camisas e logo informando que não se tratavam de policiais, mas que estavam à procura da boca de fumo. As falas de Josias e Tobias se entremeavam às falas dos garotos do tráfico (ou do movimento, como usam habitualmente na gíria local) que os acusavam de serem X9 ou policiais disfarçados. Entre um vai e vem de falas, entre um ir e vir de gestos, na cena devemos destacar que Tobias, proveniente de outra cidade e pouco habituado às dinâmicas 
das relações sociais nas periferias e favelas cariocas, ao mesmo tempo em que falava para os 'caras ficarem calmo', se despia vagarosamente, botão a botão sua camisa social velha. Enquanto Tobias desabotoava serenamente os botões de sua camisa, Josias, em certa medida atônito com o gesto do amigo, larga o verbo: 'Tobias, pare com essa porra, aqui não é show de stripper e bota a camisa caralho'. Aborrecido com o que se passava, Josias pronuncia aos traficantes que continuavam mirando os dois rapazes do carro popular: 'larguem a arma porra, abaixem essa porra, já dissemos que não somos políça (sic) e somos clientes dessa merda'. As palavras de Josias ecoam como um vento que reorienta o percurso da navegação da comunicação, permitindo com que as armas literal e metaforicamente abaixassem".

Essas notas de campo são importantes portas de entrada para esmiuçarmos o conteúdo sociológico que tangencia a questão que pretendo tratar no artigo: o modo como as relações sociais contemporâneas são marcadas pelo que denomino de um quadro social de sujeitos cismados cujas dimensões não são conformadas pela desconfiança, mas pelo cisma². Essa distinção é de suma importância para o esquema analítico proposto por mim. Embora a história narrada se passe em uma favela carioca, local por excelência de dinâmicas sociais informadas pela sociabilidade violenta (SILVA, 2004), as regiões morais do cisma se espraiam para várias camadas da vida em comum das sociedades contemporâneas. Gostaria de argumentar que mudanças históricas e sociológicas conferiram novos parâmetros para a vida em comum.

Se desconfiar é um dos dispositivos humanos mais importantes para a existência coletiva, já que na alteridade, na diferença e no estranhamento do

\footnotetext{
Gostaria de enfatizar que uso a categoria cisma como na forma habitual da língua portuguesa, qual seja, desconfiar, teimar, implicar, suspeitar etc., concedendo a ela um conteúdo analítico, propiciando assim, como fizera Mauss (em seu clássico ensaio sobre o dom e as categorias do espíirito humano) e Thévenot, para citar dois proeminentes cientistas sociais da tradição sociológica francesa, com que as categorias nativas sejam simultaneamente corpus das práticas sociais e escopo para as formulações analíticas. A entrada pelas categorias e o modo como elas repercutem na coordenação dos atores é um dos focos centrais à tradição pragmatista francesa contemporânea, vide o belo trabalho de Luc Botanski e Laurent Thévenot acerca das práticas de classificação e qualificação das coisas e das pessoas e suas implicações nos sentidos de justiça, emprestados às dinâmicas das ações dos atores em distintos mundos (BOLTANSKI; THÉVENOT, 1991). Ressalto ainda que o cisma não tem necessariamente relação com o schism do clássico e importante trabalho do antropólogo Victor Turner (1972), embora seja objeto de inspiração, mas para outro artigo.
} 
outro é que nos constituímos em nossas singularidades identitárias ou em nossa humanidade (LÉVI-STRAUSS, 1976; MEAD, 1934; RICOEUR 1990; TODOROV, 1989), o binômio confiar-desconfiar veio a se tornar central às democracias modernas. Proveniente do latim confiare (ter total fé), a confiança é um dos principais elementos morais do capitalismo e das sociedades modernas. Para um dos mais importantes teóricos do liberalismo econômico, Adam Smith, a "mão invisível do mercado" é a base para a elaboração de confianças mútuas (dos indivíduos entre eles e deles com relação ao mercado). O trust (confiança) é uma categoria chave para o funcionamento do capitalismo moderno, pois não há mercado sem confiança (SMITH, 1983). Por outro lado, nos remetendo às análises sociológicas de autores dos séculos XIX e XX, como Georg Simmel, as relações sociais do mundo moderno são marcadas pela dimensão da confiança. Para este sociólogo alemão, a economia monetária e o dinheiro refletem no modo como os indivíduos, ao quantificarem e mensurarem as coisas e as pessoas operam na elaboração dos seus repertórios e vocabulários de ação na vida em comum. A atitude mental dos sujeitos blasés imersos na vida das metrópoles consistiria, para Simmel, uma forma de adaptação, uma recusa a reagir aos estímulos como forma de acomodação aos conteúdos e ao modo de vida metropolitano, tornando o contato com o estranho uma experiência corriqueira. Essa forma de autopreservação diante das grandes cidades e que exige esse complexo aparato de viver juntos estaria atrelada ao que Simmel denominou de atitude de blasé e de reserva. Elas não estariam associadas somente à indiferença, mas a um estado de aversão, uma estranheza e repulsão mútuas contra qualquer espécie de contato com o outro. Afinal, como diria o poeta Caetano Veloso "Narciso acha feio o que não é espelho" (SAMPA, 1978), ou nos dizeres de Simmel:

Se houvesse, em resposta aos contínuos contatos externos com inúmeras pessoas, tantas reações interiores quanto às da cidade pequena, onde se conhece quase todo mundo que se encontra e onde se tem uma relação positiva com quase todos, a pessoa ficaria completamente atomizada internamente e chegaria a um estado psíquico inimaginável. Em parte esse fato psicológico, em parte o direito a desconfiar que os homens tem em face dos elementos superficiais da vida metropolitana, tornam necessária nossa reserva (SIMMEL, 1973, p. 17). 
Para Simmel, a atitude blasé e a reserva dotariam o homem metropolitano de uma liberdade que seria a contrapartida do círculo social mais amplo no qual os habitantes das grandes cidades estão inseridos. A liberdade individual se torna, portanto, uma das características fundamentais da vida nas grandes cidades, sendo ela também outro importante fundamento das democracias modernas. A confiança e a desconfiança estão no plano das dimensões das relações sociais do mundo liberal, suas estruturas morais como as conhecemos hoje estão fundadas no liberalismo dos séculos XVIII e XIX.

Por outro lado, nos reportando mais uma vez às notas etnográficas anteriormente citadas, o cisma como postulado na interação entre Josias e Tobias e os rapazes do tráfico tem uma feição sensivelmente distinta ao da desconfiança nos termos enunciados a partir das ricas contribuições de Simmel. A virada do século XXI foi marcada pelo processamento acelerado do individualismo como um dos principais meios de conferirmos sentidos à nossa existência. A diferenciação e individualização progressiva entre os indivíduos têm culminado em efeitos nas dinâmicas interacionais. Por um lado, a tendência de nos diferenciarmos um dos outros face à gramática da diferença tão presente nos espaços públicos atuais tem permitido a elaboração de encapsulamentos. Um exemplo mais evidente dos efeitos desse fenômeno das cápsulas sociais são as chamadas "bolhas" que nos envolvem no dispositivo atual denominado Facebook, em que cada uma dessas bolhas representaria uma espécie de cápsula existencial fechada, cujos procedimentos morais, gostos, ideologias e interesses devem se ajustar aos nossos. Trata-se de radicalização da lógica narcisista do poeta Caetano, já que tudo que nos é estranho é aprioristicamente e de antemão feio, ruim ou desagradável. No mundo virtual das capsulas só concedemos lugar àqueles que se enquadram aos nossos esquemas de pensamentos e predileções. Um dos efeitos desse processo é que a operação de julgamento supõe apenas um crivo: a de quem julga o outro. Esse julgamento pressupõe uma via de mão única, pois não há brechas nas relações sociais para que o julgado apresente seus motivos e condições de pertencimento ao mundo (ou sua identidade, se preferirem) no percurso da interação. Assim como no caso de Josias e Tobias, você é aquilo que determinam que você seja e pronto. A 
dimensão comunicativa que expressa a possibilidade do conserto, da negociação e do consenso se dilui concedendo lugar à comunicação de um só, na qual um fala ativamente e outro escuta sem questionamento.

Ainda, no domínio das relações cismadas o reconhecimento adquire outro conteúdo simbólico e pragmático. No lugar do princípio da dignidade humana comum, encontramos a elaboração de uma geometria variável da dignidade em que o interlocutor só reconhece a quem se conhece. Ou seja, para ascender ao status de reconhecimento, o ator necessita ser conhecido em sua substância existencial para ser dotado dos instrumentos simbólicos necessários para ser reconhecido como sujeito. Não reconhecemos indistintamente os "nossos" sem que esse outro seja filtrado pela lente do cisma, levando com que determinadas pessoas ou grupos sejam sistematicamente objeto do regime do cisma, para lançar mão de uma categoria analítica importante para nosso argumento. Na França, ponto de contraste de minhas análises com o Brasil já há muitos anos (MOTA, 2012, 2014, 2018), os efeitos das ações terroristas acentuaram sobremaneira uma relação cismada entre as instituições policiais, por exemplo, e grupos historicamente marginalizados, como os muçulmanos, africanos e negros, repercutindo-se em abordagens policiais sistemáticas contra tais grupos e revelando sérios problemas quanto à gestão do espaço público republicano devotado a conformar o comum (LÉVY, 1997).

Portanto, outra característica do cisma nos termos aqui trabalhado é a assimetria existente no plano das relações sociais, pois nesse contexto o critério de julgamento sobre o outro não se informa pela igualdade de condições mas, pelo contrário, mediante o exercício da subalternização e apagamento do outro. No quadro das relações cismadas não há lugar para a produção de um consenso sobre o julgamento a respeito da conduta alheia, já que as certezas orientam o julgamento de quem se encontra no topo da interação - e não necessariamente no topo da pirâmide social, como no caso narrado de Josias e Tobias, cujas posições na estrutura social eram mais confortáveis a dos rapazes do tráfico que os abordaram cismados com os dois -, e produz uma sentença unilateral acerca do que a pessoa é ou sobre o que a pessoa fez (ou mesmo faria). A balança da justesse é substituída pela balança do "dar ou desce". Dentro 
desse escopo interativo os meios de negociação são frágeis e sutis, requerendo um enorme esforço dos atores para que possam ser reconhecidos e que também reconheçam o outro em sua real condição humana e dignidade.

\section{O DESENHO ETNOGRÁFICO DO CISMA}

Em pesquisas que realizamos na UFF (ARAGON OVALLE, 2013, 2017; FALCÃO; MOTA, 2015; GUEDES, 2016; JULIANO, 2015; MOTA, 2005a, 2009, 2014; MOTA; DIAS NETO, 2015; PELAEZ, 2016; RIBEIRO, 2017) nos últimos anos foi possível problematizar que na arena pública brasileira o mecanismo de reconhecimento da estima social procede de forma sensivelmente distinta de outros quadros sociais, como os descritos por autores clássicos das ciências sociais e da filosofia política. No contexto brasileiro a plenitude do reconhecimento da estima social é possível mediante o conhecimento por parte dos interlocutores da substância moral digna dos indivíduos inscritos na interação (CARDOSO DE OLIVEIRA, 2002). Ou seja, na arena pública brasileira, para que aos atores sejam reconhecidos é necessário que eles sejam conhecidos em sua qualidade enquanto "pessoa", nos termos trabalhados por DaMatta (1979), para conferir a ela uma capacidade de ser reconhecida e estimada.

A partir dos desdobramentos de pesquisas coletivas de natureza etnográfica produzidas no interior do InEAC/NUFEP-UFF, fomos levados a nos interrogar as implicações da inscrição do cisma nos processos de reconhecimento das interações sociais marcadamente violentas. Em pesquisas realizadas em São Paulo, Rio de Janeiro e Minas Gerais sobre a abordagem policial (SINHORETTO et al., 2014), foi possível desenvolver diversos percursos para a compreensão da ação policial e a filtragem racial por ela promovida em sua atividade rotineira.

Tomando emprestadas as categorias como objeto por excelência da pesquisa antropológica, fomos levados a desenvolver ferramentas de análise para lidar com uma das categorias mobilizadas pelos agentes da polícia para justificarem suas predileções no ato da abordagem: o tirocínio policial ou faro 
policial. A elaboração da chamada “fundada suspeita”, ou seja, a definição arbitrária e unilateral sobre o tipo suspeito a ser abordado, se desenvolve a partir de uma diversidade de diacríticos que conferem aos indivíduos marcas que os inscrevem na mira ou faro policial. Portanto, a vestimenta (uso de determinadas marcas de roupa, bonés, estilo), a cor da pele, local no qual se encontra a pessoa na ocasião do encontro com a polícia, bem como outros elementos do corpo e do gesto constituem um complexo repertório de entendimento à ação policial e a demarcação por parte deles quanto aos sujeitos cismáveis ou não. Como muitos de nossos interlocutores apontam, os manuais de instrução, as instruções normativas e mesmo a aprendizagem na formação policial não estão orientados por um conjunto de procedimentos e protocolos que subsidiem a tomada de decisão por parte do agente policial sobre quem deve ou não ser abordado pela polícia. É o chamado faro policial que conduz o agente a promover a tal "fundada suspeita" (ARAGON OVALLE, 2017; KANT DE LIMA, 1995; KANT DE LIMA; EILBAUM; PIRES, 2017; SILVA, 1998).

De maneira geral, tanto oficiais quanto praças negam - estando eles socializados na lógica e ideologia do mito da democracia racial (ou da fábula das três raças) tão presente ainda nos dias de hoje - a prática da filtragem racial nas atividades de policiamento, creditando à fundada suspeita o mecanismo principal para a seleção daqueles que sofrem investidas da polícia. A fundada suspeita é fruto, segundo os interlocutores, da experiência que o policial adquire nas ruas para identificar um suspeito ao primeiro olhar e os signos da suspeição. Esta experiência adquirida é nomeada de tirocínio policial, uma qualidade positivada entre os agentes e construída mediante o "tempo de rua" que um policial possui.

Contudo, ainda que a prática da filtragem racial seja negada entre eles, muitos dos elementos que compõem a chamada fundada suspeita remetem a um grupo social específico, caracterizado pela faixa etária, pertença territorial e que exibe signos de um estilo de vestir, andar e falar que estão associados à cultura negra, e que é, em muitos casos, também constituinte de uma cultura “da periferia”. Não é por menos que nos últimos anos movimentos sociais em luta pela democracia e contra a violência do Estado têm ressaltado o aspecto 
brutal dessa violência no esfacelamento das vidas de jovens e de muitas famílias, denunciando com isso o curso de um genocídio do jovem negro brasileiro (MEDEIROS; EILBAUM, 2016).

A atividade da Polícia Militar no Brasil é ancorada no campo do policiamento ostensivo e a lógica no pensamento policial é a ideia de que sua atividade consiste em combater e confrontar um potencial “inimigo". Tal princípio é algo estruturante na rotina do policial, o que faz da abordagem um momento especialmente tenso e imprevisível face à lógica de combate tão presente à formação e ética policial no Brasil (ARAGON OVALLE, 2017; KANT DE LIMA, 1995; SILVA, 2011). O desfecho favorável desse momento, ao menos para o policial, dependerá da capacidade do agente em realizar a suspeição, conseguindo destacar potenciais “inimigos" do meio da multidão, antecipando e administrando assim os riscos da abordagem. Nesse contexto, alguns lugares apresentariam maior potencialidade do exercício do arbítrio policial, por exemplo, no caso das favelas, áreas periféricas, principalmente nos subúrbios cariocas, locais estes em que o regime do cisma opera com maior frequência e com maior letalidade aos cidadãos. Verificamos, assim, que a forma de administrar o conflito dependerá da natureza do suspeito, corroborando, assim, a produção de uma geometria variável da dignidade na lógica da ação policial, na qual se produzem corpos matáveis (MEDEIROS, 2018). Como apontamos na pesquisa de Sinhoretto et al. (2014), no Rio de Janeiro a policia matou durante os últimos 15 anos cerca de mil pessoas por ano por meio do chamado auto de resistência ${ }^{3}$.

Em seu documentário etnográfico, intitulado Auto de resistência, a antropóloga Natasha Neri faz emergir em inúmeras narrativas e histórias de familiares cujos parentes (filhos, sobrinhos etc.) foram vitimados pela polícia em ações

\footnotetext{
3 Segundo Misse, Grillo e Neri (2015, p. 49) o termo "auto de resistência" advém do art. 292 do Código Processual Penal (CPP), que autoriza o uso de meios necessários para "defender-se ou para vencer a resistência”, se houver resistência à prisão em flagrante. $\mathrm{O}$ artigo diz ainda que deverá ser lavrado um auto subscrito, mediante a presença de duas testemunhas, as quais são, na imensa maioria das vezes, os próprios policiais envolvidos. A tipificação penal aplicada no Registro de Ocorrência é, no entanto, o "homicídio", previsto no art. 121 do Código Penal, combinado com o art. 23, que prevê a "exclusão de ilicitude" nos seguintes casos: Art. 23 - Não há crime quando o agente pratica o fato: I - em estado de necessidade; II - em legítima defesa; III - em estrito cumprimento de dever legal ou no exercício regular de direito.
} 
em favelas ou áreas da periferia carioca, em decorrência de uma ação arbitrária sem fundamentos ou justificativas, exercidas sob o monopólio do uso da força com o extermínio dos cidadãos. Em um dos casos mostrados no filme, dois rapazes que se encontram na rua de uma favela no fim da noite brincando com seus celulares são alvejados por tiros de grosso calibre, pois os dois policiais que faziam a ronda na favela cismaram que ambos portavam armas com mira noturna, matando um dos rapazes. Em 2010, um policial do Batalhão de Operações Especiais (Bope), da tropa de elite da Polícia Militar do Estado do Rio de Janeiro (PMERJ), matou um morador da favela de Andaraí por ter confundido uma furadeira com uma arma. $\mathrm{O}$ falecido estava em sua casa pregando uma lona com a furadeira para se proteger da chuva, mas terminou não se protegendo, infelizmente, dos tiros provenientes da arma de alguém que havia cismado que se tratava de um bandido e, portanto, sujeito a ser eliminado (ZALUAR, 1985).

Nesse sentido, "concretizar a suspeita" é uma competência (ou incompetência, como nos casos anteriormente descritos) inscrita num campo em que estão tanto componentes supostamente objetivos, advindos de uma ordem técnica racionalizada e transmitida por meios institucionalizados, como por componentes que escapam totalmente à objetivação. Estes remetem a um saber informal, adquirido no cotidiano e construído "na rua", no qual o cisma opera como o critério definidor e demarcador da ação dos agentes da polícia. A materialidade do tirocínio é expressada quando o policial tem a habilidade de mapear lugares, horários, condições em que é possível realizar uma operação policial "bem sucedida", bem como quando é capaz de avaliar a existência de armas ou de objetos ilícitos a partir de uma leitura dos movimentos corporais dos transeuntes ou dos motoristas. Mais do que ser apenas um elemento suspeito, o indivíduo deve estar em atitude suspeita, ou seja, porta características de papéis sociais de sujeitos cismáveis e, portanto, objeto alvo da polícia, cujos foco tem cor, lugar e idade.

Em outra pesquisa coletiva que não vou me aprofundar aqui desenvolvida no InEAC/NUFEP-UFF (Miranda et al., 2016), com funcionários de uma concessionária de luz que prestam serviços em áreas de "risco" (as denominadas 
favelas), inúmeras narrativas enfatizavam a imprevisibilidade das relações sociais presente no cotidiano do trabalho nas favelas mediante a abordagem dos traficantes cismados com os funcionários sob a suspeita de eles pertencerem à polícia ou a grupos de outras facções criminosas, bem como da ação policial contra os próprios, confundindo-os com agentes do tráfico. Os nossos interlocutores apresentaram uma diversidade de situações nas quais foram objeto do cisma por parte de traficantes na ocasião em que foram abordados com armas de grosso calibre pelo fato de serem identificados como "alemão".

As diversas narrativas, representações e discursos apresentados ao longo das pesquisas pelos nossos interlocutores permitiu que eu desenvolvesse alguns quadros de referência sobre as geometrias variáveis da dignidade, particularmente em interações sociais marcadas por uma sociabilidade violenta (SILVA, 2004), imprevisível e, ainda, fortemente regida pelo regime do cisma. Neste registro, os detentores do monopólio da violência - policias ou traficantes - suspendem a possibilidade de argumentação dos atores submetidos a ação violenta, na qual sua marca identitária é imposta pelo assujeitador que a torna a referência daquilo que a pessoa é ou deva ser. No regime do cisma o sujeito é encapsulado numa caixa que delimita a possibilidade de argumentação que contrarie o rótulo do assujeitamento, concedendo à interação um grau imensurável de imprevisibilidade diante do fato que o policial ou traficante cismou com você. Tomo emprestado, posteriormente, uma das narrativas. Ela nos permite delinear as características das interações sociais no regime do cisma, demonstrando como ela parece se conformar enquanto uma instituição com regras de procedimentos cabíveis de socialização para aqueles que constituem as fileiras de tais grupos. Logo, o cisma não pode ser pensado como uma expressão que se acomoda aos traços pessoais de determinados sujeitos, mas que se constitui em um dispositivo disponível para os procedimentos de vigilância, de operação das classificações de identidades e exercício da discricionariedade marcante na sociabilidade dos territórios periférico das grandes cidades brasileira, mas que são espraiadas às outras realidades do mundo contemporâneo. Como nos narra um funcionário da concessionária de luz com pouco mais de 30 anos: 
Fomos instalar caixa de correio em Santa Isabel para que as contas não se perdessem, quando faltavam apenas três para finalizar o serviço, grita um cara: "meninos, para aí", pô, olhamos assim espantados, aí eles: "levanta a blusa, dá uma rodadinha. Vocês tão fazendo o que aqui? Se vieram mandado vão tomar, hein". Os caras tudo com R15, pistola, aí tem que se explicar direitinho: "a gente tá instalando caixa de correio e os moradores tão reclamando muito que as contas não tão chegando, que a gente pendura no portão e a molecada tira, aí a gente tá instalando". Aí ele falou: "vocês vão instalar essa caixa de correio onde?". "Casa de Dona x, número y". "Ih, ela mora bem ali". Levou eles até a casa e bateu no portão, "ai bateu, a senhora pediu alguma caixa de correio?!”. Ela falou “não!”. Tá vendo essa menina branca? (se referindo a uma das assistentes do Grupo Focal) Eu fiquei mais branco que ela. A perna tremia, a voz não sai, não sai palavra nenhuma, não conseguia falar. "Cala a boca! Fala um de cada vez!”. Quando a mulher falou: “eu não pedi nada!”, o cara falou: "Que história é essa? Tem um amigo meu, nós não somos dessa área aqui, outro cara que entrega aqui, nós só viemos instalar as caixas de correio". Aí a mulher ouviu e isso falou que a gente realmente não trabalhava naquela área, "realmente quem trabalha aqui é outro amigo meu. Ele coloca a conta aqui e os moleques pegam". "Aí o cara, tudo bem, pode colocar essa caixa de correio. Show de bola”. Aí começamos a instalar, tremendo, e ele voltou: "peraí, tem alguma coisa errada aqui, não é o Correio que entrega a correspondência? Vocês passaram devem ter alguma coisa". "Não, não meu amigo, tem nada aqui não". O cara falou pra um moleque: "moleque, vai lá fora de bicicleta, na rua principal e vê se tem algum carro de polícia parado lá. Você só faz assim e assim" (sinalizou os sinais de positivo e negativo com as mãos). Aí olhou pra gente e falou assim: "rapaziada, pode ir andando, a arma que tô aqui pega vocês ali na esquina”. Se tivesse um caro parado lá, eu não taria aqui. O cara tava o capeta, o cara tá o demônio, queria matar a gente. Os moleques passaram pela gente e falaram: "vocês deram mó sorte, ein?". É uma situação que você passa e fica doido. Quando a mulher falou pra gente não pediu nada... Lá é outra realidade. Nego cisma. (MIRANDA et al., 2016, informação verbal)

Essa descrição densa das relações sociais marcadas pelo cisma e a sociabilidade violenta demonstram como as microrregiões da vida social nesses 
contextos são informadas pela complexa definição de diacríticos responsáveis para que se legitime ou não o cisma, delineando a fronteira entre o morrer ou viver, demonstrando que nesses momentos há uma ruptura de um dos princípios basilares das interações sociais nas sociedades contemporâneas: a conjugação entre a confiança e a possibilidade do acordo. Estes dois elementos são suprimidos no percurso da relação cismada, promovendo um desequilíbrio da relação de poder existente entre o sujeitado e o assujeitador.

As características das relações cismadas se distinguem daquelas analisadas por Simmel, em particular às que se referem ao mundo da indiferença das grandes metrópoles que conformam uma gestão das políticas das identidades marcadas pelo princípio da competência e consciência que os atores dispõem para formularem consensos provisórios e exporem e suas identidades e papéis explicitamente e de forma negociada com seus interlocutores (MEAD, 1934). Pelo contrário, no cisma as identidades são gerenciadas unilateralmente pelo detentor do monopólio de definir as referências da interação unilateral, na qual um fala e outro escuta.

Nessa direção, o funcionamento dos princípios da geometria variável da dignidade e do reconhecimento ganha enorme potência para o delineamento das sensibilidades sobre o justo e o adequado. Neste registro, os detentores do monopólio da violência - policias ou traficantes - suspendem a possibilidade de ações comunicativas simétricas (HABERMAS, 1993) alocando a situação de interação para um plano no qual as definições identitárias estão sob o crivo do ator que assujeita o outro à uma identidade enquadrada pelo assujeitador. ]Uma das consequências sociológicas desse fenômeno é o fato de que a identidade definida pelo agente cismado (identidade virtual) se torna, ainda que momentaneamente, o papel social (GOFFMAN, 2001) principal do ator assujeitado, subvertendo o princípio da universalidade da dignidade que supõe a confiança e a estima do interlocutor, bem como das regras de interação do mundo liberal em que cada qual possui a legitimidade para dizer o que é ou representa ao mundo e no mundo.

O universo do cisma e da sociabilidade violenta aparece delineado pela relativização da confiança, do reconhecimento e da dignidade que os atores 
portam nas interações. Há uma disjunção e suspensão entre a confiança e a possibilidade de acordo no regime do cisma, promovendo um desequilíbrio da relação entre reconhecimento, dignidade e justesse tão caro às democracias contemporâneas. A balança do cisma opera com enorme frequência entre policiais, como relatado por um dos entrevistados, um policial de mais ou menos 40 anos, capitão da PMERJ:

Pois é assim professor, uma vez a gente tava numa operação que pegamos uma moleques do tráfico. Pegamos os moleques e botamos tudo no canto, sentado, demos umas porradas neles e aí tinha que dar uma lição... Eles trocaram tiro com a gente e não tinha o que fazer se não dar uma lição. Aí cismamos com um lá, cismamos porque ele era o mais jeito de bandidinho e passamos ele pra dar uma lição [...]. (Notas de campo)

Essa entrevista nos aponta como o cisma é um dispositivo de ação que opera no sentido de invisibilizar e aniquilar a humanidade alheia, fornecendo inclusive a legitimidade aos policiais para exercerem o poder de eliminar uma vida sem que ela possa ser filtrada pelo canal da dignidade e humanidade. No Brasil e no mundo, o cisma mata, e mata muito!

\section{OS CAMINHOS PARA ALGUMAS CONSIDERAÇÕES}

A difusão da questão do reconhecimento nas ciências sociais em geral nos convida a questionar os projetos ideológicos que visam modelá-la. Ela pode deter um papel de denunciação e crítica da opressão vivida por grupos minoritários ou não, assim como propõe certa sociologia, mas também pode servir de instrumento analítico relativo às inquietudes e preocupações relacionadas com o modo como os atores se apropriam desses princípios para dar visibilidade às suas demandas públicas. Assim, buscando diferenciar as formas ideológicas e as formas justificadas de reconhecimento, marcando justamente que a realização do reconhecimento não ganha a mesma forma nos distintos casos de interações (HONNETH, 2000; THÉVENOT, 2006), nossa preocupação está 
relacionada com a atenção destinada às provas de justificações e críticas a que os atores são submetidos, visando delinear os distintos quadros de reconhecimento, como discutido por Laurent Thévenot, e as múltiplas noções de igualdade como proposto por Luís Roberto Cardoso de Oliveira, cujos artigos compõem este dossiê.

Nos últimos anos, a partir de pesquisas desenvolvidas no interior do NUFEP, no PPGA e no InEAC da UFF, temos nos dedicado a refletir sobre as operações elaboradas pelos atores nas demandas de direitos e reconhecimento em diferentes contextos políticos, morais e simbólicos (ARAGON OVALLE, 2013; CARDOSO DE OLIVEIRA, 2002; MOTA, 2014; RIBEIRO, 2017). No âmbito do grupo de pesquisa por mim coordenado, inúmeros trabalhos de natureza etnográfica vislumbraram explorar os aspectos pragmáticos das demandas de reconhecimento formuladas nos diferentes contextos sociais. Nos casos da Marambaia, Sacopã e Grotão, por exemplo, o exercício contínuo na produção e reprodução de uma identidade quilombola veio conferir visibilidade e legitimidade às demandas de direitos dos moradores assentados numa gramática do reconhecimento de suas particularidades e singularidades identitárias.

Nessa direção, os trabalhos desenvolvidos pelo grupo de pesquisa têm se esforçado a analisar o modo pelo qual determinadas identidades e papéis sociais adquirem (ou não) visibilidade na esfera e espaço público brasileiro (MOTA 2009, 2014, 2015) diante de um quadro informado por uma geometria variável da dignidade que relativiza e consubstancia o reconhecimento (ou desconhecimento) da substância moral da dignidade dos atores nas arenas públicas (CARDOSO DE OLIVEIRA, 2002). As questões apresentadas pelas pesquisas que desenvolvemos nos encaminharam para um refinamento analítico e contrastivo acerca da variação e modulação dos princípios da igualdade, da liberdade e da dignidade presentes nas políticas contemporâneas do reconhecimento. Particularmente, buscamos nos interrogar sobre os efeitos da introdução nos sistemas políticos e morais das noções modernas de indivíduo (DUMONT, 1992, 1983) e suas implicações na configuração das gramáticas do reconhecimento e da dignidade no mundo contemporâneo (HONNETH, 2000; RICOEUR, 2004). 
Talvez o que a modernidade tenha emprestado de comum aos diferentes quadros de interação social seja a centralidade das categorias como dignidade, justesse e decência nas formas tomadas pelos dispositivos políticos e morais, repercutindo nos modos como atores mobilizam-se e coordenam suas ações no cenário político. Ao mesmo tempo, a busca pelo "tratamento decente" se tornou uma via pela qual os grupos canalizam suas demandas de reconhecimento de uma dignidade universal e da validação do princípio de justesse que passa a organizar as instituições da esfera pública (MARGALIT, 1999).

Por outro lado, diferentes quadros teóricos desenvolvidos para além dos grandes centros acadêmicos europeus ou do norte lançam questões relevantes para conceber novas formas de construção de reconhecimento, como na arena pública brasileira cujas relações sociais estão marcadas por um forte viés hierárquico e personalista, no qual a gramática da sociabilidade violenta (SILVA, 2004) adquire enorme notabilidade nos ritmos das interações sociais nos meios urbanos das grandes cidades brasileiras, em particular nas denominadas regiões periféricas. Esse quadro é ainda incrementado com novas formas marcantes às relações face-to-face a partir da presença de dois outros regimes marcantes na arena pública brasileira: o da sujeição criminal (MISSE, 2010) e da inquisitorialidade (KANT DE LIMA, 2008). De acordo com Silva (2004), a sociabilidade violenta presente nas grandes áreas periféricas da cidade do Rio de Janeiro leva a relação social ao paroxismo de forma tal que os agentes sociais fazem do medo e da desconfiança elementos conformadores das relações sociais. Nesse sentido, a associação e a articulação entre os princípios da sociabilidade violenta, o da sujeição criminal e da inquisitorialidade, impõem uma dinâmica distinta às relações sociais daquelas perspicazmente analisadas por autores dedicados a refletir sobre as vicissitudes do reconhecimento na contemporaneidade, como Margalit, Honeth, Taylor, Boltanski, Thévenot, Ricoeur, dentre outros. No quadro analítico desses autores, o processo de reconhecimento social pressupõe a uniforme e simétrica distribuição da dignidade entre os atores das arenas públicas (RICOUER, 2004). Primeiro, porque como salienta Misse, a sujeição criminal pode ser considera como um processo de criminação de sujeitos, e não de cursos de ação. Trata-se de um sujeito que "carrega" o 
crime em sua própria alma; não é alguém que comete crimes, mas que sempre cometerá crimes, um bandido, um sujeito perigoso, um sujeito irrecuperável, alguém que se pode desejar naturalmente que morra, que pode ser morto, que seja matável. No limite da sujeição criminal, o sujeito criminoso é aquele que pode ser morto. Originalmente, a sujeição criminal é apenas distintiva. Nesse sentido, ela sempre começa no plano da interação social contextual, mas já sob a referência estrutural do "criminal". O referente está dado não apenas nos códigos penais, mas na própria linguagem que na interação será empregada para distinguir a ruptura da normalidade ou a sua expectativa em um sujeito (MISSE, 2010). E num segundo plano, porque a inquisitorialidade, como enfatiza Kant de Lima, faz parte da tradição judicial brasileira (e está presente em sua sensibilidade jurídica) e nela o sistema de produção de verdades judiciárias valoriza positiva e explicitamente o conhecimento detido de forma particular, não universalmente disponível na sociedade: quem pergunta sempre sabe mais do que quem responde e é deste saber que advém a autoridade do seu discurso. Decorrem daí, inclusive, regimes retóricos distintos daqueles da argumentação que busca o consenso: aqui predomina o embate escolástico de teses opostas, em que apenas uma deve ganhar, por ter saber mais autoritativo do que o da outra. Vale o argumento de autoridade, em prejuízo da autoridade dos argumentos (KANT DE LIMA, 1999).

Essas diferenças existentes entre os quadros teóricos e os sociais tornam frutífero compreendermos a vida social por meio do conflito, dos dramas sociais, dos desajustes, dos acordos e desacordos, das justificações e modulações de reconhecimento, de modo a garantir uma ordem mais heterogênea e plural das sociedades modernas. Interrogações sobre o modo de habitar as sociedades complexas, a coabitação entre indivíduos, a vivência do sentimento de compartilhamento, e simultaneamente compartimentalização dos laços e identidades sociais, tornaram as sociedades complexas uma verdadeira equação entre a luta pelo reconhecimento e a luta dos indivíduos, como assinala Simmel (1979).

Paul Ricoeur, em um de seus célebres livros, Percurso pelo reconhecimento, elabora uma análise antropologicamente sofisticada sobre as alterações 
impostas às configurações dos sujeitos advindas das transformações vivenciadas pela passagem do "estado de natureza hobessiano" ao "estado cívico hegeliano". Ao passo que no primeiro, a luta pela sobrevivência e a maximização dos benefícios reinariam (na luta de todos contra todos), no segundo da luta pelo reconhecimento, regido pelas paixões e intersubjetividades, desenvolveria um sentimento de pertencimento ao mundo no qual a produção do self implicaria na extensão de uma consciência de si-para-o-outro.

Nesses termos, o mundo cívico hegeliano ocupa um espaço do universo leviataníco quanto à composição de uma nova forma de entendimento sobre a "identidade". No lugar dos instintos, as paixões; no lugar dos interesses, as emoções regidas pelos imperativos do reconhecimento. Como assinala Paul Ricoeur (2004, p. 220):

C'est sur Le parcours de La volonté que Le thème de la reconaissance apparaît dans la première partie, parcours marque par la maîtrise du moi sur les images, par La position de soi dans l'interiorisation par l'appelation que fait maître des noms, et par Le règne de La conceptualisation. Ce parcours de La volonté est celui de la résolution (belchluss) et de son argumentation (schluss) ou "syllogisme". Nous retrouverons dans ce cadre la pulsion, Trieb, son manque et as satisfaction; 1'outil, sa singularité et sa capacité universelle des choses; nous retrouvons aussi l'amour, l'homme et la femme, la famille, millieu électif de l'éducation, en conjunction avec le travail, et surtout l'enfant, ce tiers en qui les parents instituionnent l'amour

Nessa pluralidade ordenada de modelos de reconhecimento (Ricoeur), a intersubjetividade e as motivações morais propiciariam a constituição de uma pluralidade de consciências que poderiam ser antropologicamente sintetizadas com a fórmula hegeliana être soi-même dans un étranger (RICOUER, 1990). A experiência da vida, nesse sentido, é a de transações entre as diferentes esferas que compõem o sujeito no mundo hegeliano: um eu, um mim e um nós. O alargamento de uma consciência de si através de um outro confere um plano radical de alteridade entre um nós e eles. Ou seja, funda-se um universo interacional no qual as identidades ganham formas contratuais de 
trocas de bens de natureza simbólica e moral. Em grande medida a aquisição de uma identidade autêntica (no sentido da autenticidade de Charles Taylor, 2000) tornar-se-ia um imperativo para as motivações e ações dos atores no mundo da luta pelo reconhecimento.

Esse quadro delineia duas dimensões importantes da vida política moderna: a extensão do individualismo igualitário e seus impactos na promoção de um encapsulamento identitário, informado pela lógica do todos juntos porém separados, próprio do modelo liberal (Dumont); e a equação da relação entre irredutibilidade de um eu e sua extensão de um outro nos termos proposto pelo iluminismo universalista republicano (MOTA, 2014). Georg Simmel (1979), nas primeiras páginas de um dos seus trabalhos ao qual nos remetemos, "A Metrópole e a vida mental", reivindica o pensamento do filósofo Nietzsche para subsidiar sua compreensão e análise sobre o processo de individualização e metropolização das relações sociais contemporâneas realçando a percepção de seu compatriota que o "pleno desenvolvimento do indivíduo está condicionado pela mais impiedosa luta de indivíduos" (SIMMEL, 1979, p. 15). A arguta observação de Simmel acerca da produção e conformação de uma sociedade de indivíduos ambientando em um universo do individualismo igualitário, fornece-lhe a possibilidade de elaborar um perfil socioantropológico do "indivíduo blasê", cujas características fundamentais são: a distância social, a indiferença relativa e a impessoalidade propiciadas pela "psique metropolitana", como ressaltamos anteriormente.

As mudanças impostas nas relações sociais no mundo contemporâneo têm, nos últimos 60 anos, exigido às matrizes disciplinares das ciências sociais se renovar quanto ao manuseio dos aparatos teóricos-metodológicos mobilizados pelos cientistas sociais.

O trabalho do cientista social exige um lento e artesanal exercício de emolduração (e também de maturação) dos diversos componentes que permitem o delineamento, pincelamento e interpretação dos fenômenos sociais em suas múltiplas cores, formas e aparatos que regem a vida social. Nesse percurso analítico, a irregularidade, a imprevisibilidade, a incoerência e a instabilidade se instauram como elementos intrínsecos às dinâmicas da vida associativa e da 
socialidade marcantes das democracias plurais dos dias atuais. Neste contexto, o vivre-ensemble exige dos atores um emaranhado de enunciados, justificações e gestos que conferem uma multiplicidade de possibilidades de produção do consenso no dissenso (BOURDIEU, 1972).

A heterogeneidade de formas, representações, expressões, ideologias, sentimentos alimentados pelos atores nos mundos plurais e compósitos não implicam diluição da uniformidade (e em certa medida regularidade) quanto às diferentes formas de expressão de pertencimento e apresentação de si (GOFFMAN, 2001). Pelo contrário, essa relativa uniformidade da vida social, como já salientavam os sociólogos Émile Durkheim e Marcel Mauss, resulta da estabilização proposta pelos sistemas classificatórios que consistem em classificar as coisas a partir das formas humanas de modelar o mundo. As classificações das coisas reproduzem as classificações dos homens, já afirmaram Durkheim e Mauss, inaugurando uma abertura para um canal que desembocaria na formulação de uma antropologia das categorias e das classificações tão caro sobretudo à sociologia francesa.

Ao longo de sua história, as ciências sociais concederam outras dimensões às categorias sociológicas (e sociais) de modo a propiciar que elas se tornassem uma das portas privilegiadas para a análise dos fenômenos sociais. Nesse sentido, tal porta tem servido à compreensão das moralidades, sentimentos e práticas inscritas e circunscritas às categorizações e organização do mundo social, assim como tem permitido a operação analítica mediante as análises dos sentidos por elas emprestados às práticas dos atores em suas diferentes versões do viver em sociedade.

Nesses termos, as categorias comportariam fundamentos inconscientes (nos termos de Lévi-Strauss) que sedimentam as formas e modos de fazer o comum. Ela nos fornece o acesso ao universo recôndito da vida social, fazendo com que desabrochem e floresçam as nuances do fazer o comum. O exercício de observar, reunir e compreender (DUMONT, 1992) tornam, aos olhos do cientista social, as categorias em um objeto de desvelamento dos quadros de significados que definem a moldura de um contexto de uma interação. Ora, como formulado por muitos autores (BOLTANSKI, 1992; DESROSIÈRES; THÉVENOT, 1988), as categorias não podem ser entendidas dissociadas das 
gramáticas políticas e morais que conferem densidade às formas de agir. A partir de um exercício antropológico e, portanto, etnográfico, busquei discutir o lugar que a categoria cisma-cismar ocupa nas dinâmicas sociais contemporâneas.

Busquei problematizar que a equação entre reconhecimento e dignidade tem sido abalada nas últimas décadas pelo rompimento das barragens do liberalismo. Na Europa, por exemplo, os efeitos e repercussões dos atentados ao longo do ano de 2015 em Paris (ao jornal Charlie Hebdo e aos bares, restaurantes e estádio), desencadearam em uma série de reações e ações em defesa da liberdade de expressão, da laicidade, da República, por um lado. Em contrapartida, ataques a mesquitas, insultos verbais, o preconceito e as formas de ação policias vieram reforçar os estigmas e os mecanismos de controle de determinados grupos e atores a partir do cisma, produzindo uma ruptura com o princípio do contrato social rosseauniano tão caro à democracia francesa e excluindo cada vez mais uma massa de franceses que nutrem um sentimento de serem français à part entière ou entièrement à part (franceses em toda parte ou franceses inteiramente à parte).

Esse drama social que se repercutiu nas entranhas da République resultou no abalo na gestão da integração e assimilação à francesa - já que se tratava de um atentado promovido por cidadãos e nacionais franceses - e suas implicações na conformação de um espaço público representado pelas noções contratuais do "comum" e da "confiança". Nesse sentido, o regime do cisma parece ganhar um contorno central às sociedades contemporâneas, matando pessoas e talvez, pouco a pouco, a própria democracia...

\section{REFERÊNCIAS}

1. ARAGON OVALLE, Luiza. Entre a casa e a política: uma etnografia das controvérsias na ladeira Sacopã. 2013. Dissertação (Mestrado em Antropologia) - Universidade Federal Fluminense, Niterói, 2013.

2. ARAGON OVALLE, Luiza. A memória que não leva à justiça: uma etnografia das moralidades e dos discursos presentes no Tecnólogo em Segurança Pública e Social da Universidade Federal Fluminense. 2017. Tese (Doutorado em Antropologia) Universidade Federal Fluminense, Niterói, 2017. 
3. AUTO de resistência. Direção Natasha Neri e Lula Carvalho. Rio de Janeiro: Com Domínio Filmes, 2018.

4. BREVIGLIERI, Marc. Pensar a dignidade sem falar de linguagem da capacidade em agir: uma discussão crítica sobre o pragmatismo sociológico e a teoria do reconhecimento de Axel Honneth. Terceiro Milénio, Revista Crítica de Sociologia e Política, Campo dos Goytacazes, v. 6, n. 1, p. 11-34, jan.-jun. 2016.

5. BOLTANSKI, Luc. L'amour et la justice comme compétences: trois essais de sociologie de l’action. Paris: Editions Métailié, 1992.

6. BOLTANSKI Luc; THÉVENOT, Laurent. De la justification: les économies de la grandeur. Paris: Gallimard, 1991.

7. BOURDIEU, Pierre. Esquisse d'une théorie de la pratique: précédé de trois études d’ethnologie kabyle. Genève: Librairie Droz, 1972.

8. CARDOSO DE OLIVEIRA, Luís. Direito legal e insulto moral: dilemas da cidadania no Brasil, Quebec e EUA. Rio de Janeiro: Garamond, 2002.

9. DAMATTA, Roberto. Sabe com quem está falando? Um ensaio sobre a distinção entre indivíduo e pessoa no Brasil. In: DAMATTA, Roberto. Carnavais, malandros e heróis: para uma sociologia do dilema brasileiro. Rio de Janeiro: Zahar, 1979. p. 179-248.

10. DESROSIÈRES, Alain; THÉVENOT, Laurent. Les catégories socioprofessionelles. Paris: Editions La Découverte, 1988.

11. DUMONT, Louis. Essais sur l'individualisme: une perspective anthropologique sur l'idéologie moderne. Paris, Seuil. 1983.

12. DUMONT, Louis. Homo hierarchicus: o sistema de castas e suas implicações. São Paulo: Edusp, 1992.

13. FALCÃO, Hully Guedes; MOTA, Fabio Reis. Infringir para resistir: mobilizações coletivas dos pescadores de Atafona - São João da Barra (RJ). Avá, Misiones, v. 26, p. 107-124, 2015.

14. FREIRE, Jussara. Des émotions aux revendications: voix et souffrance de « mères de victimes de violence policière » à Rio de Janeiro. SociologieS, Paris, 2018.

15. GOFFMAN, Erving. A representação do eu na vida cotidiana. Petrópolis: Vozes, 2001.

16. GUEDES, Lucía Copelotti. Sobre (N)atureza(s) e cosmologias em disputa: controvérsias em torno das práticas rituais de religiões de matriz afro-brasileira no espaço público em Cachoeiras de Macacu, RJ. 2016. Dissertação (Mestrado em Antropologia) - Universidade Federal Fluminense, Niterói, 2016. 
17. HABERMAS, Jürgen. L'espace public: archéologie de la publicité comme dimensión constitutive de la société bourgeoise. Paris: Payot, 1993.

18. HONNETH, Axel, La lutte pour la reconnaissance. Paris: Le Cerf, 2000.

19. JOSEPH, Isaac. Le passant considerable: essai sur la dispersion de l'espace public. Paris: Meridiens, 1984.

20. JULIANO, Filipe Romão. Vivendo de resistência: o Quilombo Sacopã, o Estado, o samba e a luta por reconhecimento. 2015. Dissertação (Mestrado em Antropologia) Universidade Federal Fluminense, Niterói, 2015.

21. KANT DE LIMA, Roberto. A polícia da cidade do Rio de Janeiro: seus dilemas e paradoxos. Rio de Janeiro: Forense, 1995.

22. KANT DE LIMA, Roberto. Polícia, justiça e sociedade no Brasil: uma abordagem comparativa dos modelos de administração de conflitos no espaço público. Revista De Sociologia e Política, Curitiba, n. 13, p. 23-38, nov. 1999.

23. KANT DE LIMA, Roberto. Ensaios de Antropologia e de Direito: acesso à justiça e processos institucionais de administração de conflitos e produção da verdade jurídica em uma perspectiva comparada. Rio de Janeiro: Lúmen Júris, 2008.

24. KANT DE LIMA, Roberto; EILBAUM, Lucía; PIRES, Lenin dos Santos. Lógicas corporativas, particularismos e os processos de administração institucional de conflitos no Rio de Janeiro. Confluências, Niterói, v. 19, p. 18-35, 2017.

25. LÉVI-STRAUSS, C. Raça e História. In: Antropologia Estrutural dois. Rio de Janeiro: Tempo Brasileiro, 1976. p. 328-366.

26. LÉVY, René. A crise do sistema policial francês hoje: da inserção local aos riscos europeus. Tempo Social, São Paulo, v. 9, n. 1, p. 53-77, maio 1997.

27. MARGALIT, Avishai. La societé decente. Paris: Edition Climats. 1999.

28. MAUSS, Marcel. Ensayo sobre los dones: razon y forma del en las sociedades primitivas. In: MAUS, Marcel. Sociologia y Antropología. Madrid: Tecnos, 1971a.

29. MAUSS, Marcel. Sobre una categoria del espirito humano: la nocion de persona y la nocion del “yo". In: MAUS, Marcel. Sociologia y Antropología. Madrid: Tecnos, $1971 \mathrm{~b}$.

30. MEAD, George Herbert. Mind, self and society. Chicago: University of Chicago Press, 1934.

31. MEDEIROS, Flavia. Linhas de investigação: uma etnografia das técnicas e moralidades numa divisão de homicídios da Polícia Civil do Rio de Janeiro. Rio de Janeiro: Autografia, 2018. v. 1. 
32. MEDEIROS, Flavia; EILBAUM, Lucia. “Onde está Juan?": moralidades e sensos de justiça na administração judicial de conflitos no Rio de Janeiro. Anuário Antropológico, Brasília, DF, v. 41, p. 9-33, 2016.

33. MIRANDA, Ana Paula et al. Relatório de pesquisa qualitativa: acesso e circulação de profissionais em áreas de risco e atuação da empresa Enel. Niterói, UFF, 2016.

34. MISSE, Michel. Crime, sujeito e sujeição criminal: aspectos de uma contribuicão analítica sobre a categoria "bandido". Lua Nova, São Paulo, n. 79, p. 15-38, 2010

35. MISSE, Michel; GRILLO, Carolina; NERI, Natasha. Letalidade policial e indiferença legal: A apuração judiciária dos 'autos de resistência' no Rio de Janeiro (20012011). Dilemas, Rio de janeiro, Edição Especial n. 1, p. 43-71, 2015.

36. MOTA, Fabio Reis. O Estado contra o Estado: direito, poder e conflitos no processo de produção da identidade "quilombola" da Marambaia. In: KANT DE LIMA, R. (org.). Antropologia e Direitos Humanos 3. Niterói: Eduff, 2005a. p. 133-184.

37. MOTA, Fabio Reis. Conflictos, multiculturalismo y los dilemas de la democracia a la brasileira. In: TISCORNIA, Sofia; PITA, María Victoria. (eds.). Derechos humanos, tribunales y policías en Argentina y Brasil. Buenos Aires: Antropofagia, 2005b.

38. MOTA, Fabio Reis. Manda quem pode e obedece quem tem juízo? Uma reflexão antropológica sobre disputas e conflitos nos espaços públicos brasileiro e francês. Dilemas, Rio de Janeiro, v. 2, n. 4, p. 107-127, 2009.

39. MOTA, Fabio Reis. Regimes de envolvimento e formas de reconhecimento no Brasil e na França. Antropolítica, Niterói, n. 32, p. 129-147, 2012.

40. MOTA, Fabio Reis. Cidadãos em toda parte ou cidadãos à parte? Demandas de direitos e reconhecimento no Brasil e na França. Rio de Janeiro: Consequência, 2014.

41. MOTA, Fabio Reis; DIAS NETO, José C. The making of the common in the development of social identities: how to be or not to be a fisherman in Brazil and Portugal. In: RESENDE, José Manuel; MARTINS, Alexandre Cotovio. (eds.). The making of the common in social relations. Cambridge: Cambridge Scholars Publishing, 2015.

42. MOTA, Fabio Reis. Les arènes publiques identitaires: des antillais de Paris aux quilombos de Rio de Janeiro, une comparaison France/Brésil. SociologieS, Paris, 2018.

43. PELÁEZ, Daniela. Nomeando o inominável: identidade, afirmação, atribuição e acoplamento no quilombo do Grotão. 2016. Dissertação (Mestrado em Antropologia) - Universidade Federal Fluminense, Niterói, 2016. 
44. RIBEIRO, Yolanda G. Os limites da Reforma Agrária e as fronteiras religiosas: os dilemas dos remanescentes de quilombo do Imbé. Rio de Janeiro: Autografia, 2017. v. 80.

45. RICOEUR, Paul. Soi-même comme un autre. Paris: Seuil, 1990.

46. RICOEUR, Paul. Parcours de la reconnaissance. Paris: Gallimard, 2004.

47. SAMPA. Caetano Veloso. Rio de Janeiro: CBD Phonogram, 1978.

48. SILVA, Jorge da. Violência e racismo no Rio de Janeiro. Niterói: Eduff, 1998. (Antropologia e Ciência Política, v. 14).

49. SILVA, Luiz Antonio Machado da. Sociabilidade violenta: por uma interpretação da criminalidade contemporânea no Brasil urbano. Sociedade e Estado, Brasília, DF, v. 19, n. 1, p. 53-84, 2004.

50. SILVA, Robson Rodrigues da. Entre a caserna e a rua: o dilema do pato. Niterói: Eduff, 2011. (Antropologia e Ciência Política, v. 52).

51. SIMMEL, Georg. A metrópole e a vida mental. In: VELHO, Otávio Guilherme (org.). O fenómeno urbano. 4. ed. Rio de Janeiro: Zahar, 1979.

52. SMITH, Adam. A riqueza das nações: investigação sobre sua natureza e suas causas. São Paulo: Abril Cultural, 1983.

53. SINHORETTO, Jacqueline et al. A filtragem racial na seleção policial de suspeitos: segurança pública e relações raciais. In: LIMA, Cristiane do Socorro Loureiro; BAPTISTA, Gustavo Camilo; FIGUEIREDO, Isabel Seixas de (orgs.). Segurança pública e direitos humanos: temas transversais. Brasília, DF: Secretaria Nacional de Segurança Pública, Ministério da Justiça, 2014. p. 121-158. (Pensando a segurança pública, v. 5).

54. TAYLOR, C. Argumentos filosóficos. São Paulo: Edições Loyola, 2000.

55. THÉVENOT, Laurent. Constituer l'environnement en chose publique: une comparaison franco-américaine. In: BLAIS, Jean-Paul; GILLIO, Claire; ION, Jacques. Cadre de vie: environnement et dynamiques associatives. Paris: Puca, 2001. p. 203-219.

56. THÉVENOT, Laurent. L'action au pluriel. Paris: La Decouverte, 2006.

57. TODOROV, Tzvetan. Nous et les autres: la réflexion française sur la diversité humaine. Paris: Seuil, 1989. (Col. La couleur des idées).

58. TURNER, Victor. Schism and continuity in an african society: a study of Ndembu village life. Manchester: Manchester University Press, 1972.

59. ZALUAR, Alba. A máquina e a revolta: as organizações populares e o significado da pobreza. São Paulo: Brasiliense, 1985. 